\title{
Studies on the Synthesis of 2,6-Disubstituted Dihydropyrans: Intervention of Oxonia-Cope Rearrangements in the Lewis Acid Mediated Cyclodehydrative Reactions of Aldehydes and $\beta$-Hydroxyallylsilanes
}

\author{
William R. Roush,* Garrett J. Dilley ${ }^{1}$ \\ Department of Chemistry, University of Michigan, Ann Arbor, Michigan 48109-1055, USA \\ Fax +1 734 6479279; E-mail: roush@umich.edu \\ Received 22 January 2001 \\ Dedicated to Professor Ryoji Noyori in admiration of his seminal contributions to organic chemistry.
}

Abstract: The dehydrative coupling reactions of anti- $\beta$-hydroxyallylsilanes $\mathbf{5}$ and aldehydes provide 2,6-cis-dihydropyrans 27 by pathways involving oxonium ions that cyclize via boat-like transition state 21, with the intervention of oxonia-Cope rearrangements $(21 \rightarrow 29)$.

Key words: addition reactions, intramolecular allylations, sigmatropic rearrangement, allylsilanes, dihydropyrans

During the course of our work on the total synthesis of scytophycin $\mathrm{C}^{2}$, we became interested in developing a new strategy for synthesis of the 2,6-trans disubstituted dihydropyran nucleus of $\mathbf{4}$ by the late stage coupling of two advanced aldehyde fragments (1 and 2) with the bifunctional allylating agent, $\mathbf{3}\left(\mathrm{X}_{2}=\right.$ DIPT or $\left.\mathrm{Ipc}_{2}\right){ }^{3,4}$ While numerous strategies for synthesis of substituted pyrans are available, ${ }^{5}$ none have the potential modularity of the method that we sought to develop.

The plan was that $\beta$-hydroxyallylsilanes $\mathbf{5}$, which are available with high diastereo- and enantioselectivity via the asymmetric $\gamma$-silylallylboration of aldehydes with allylborane reagents $3,3,4,6$ would combine with a second aldehyde in the presence of a Lewis acid to give oxonium ion 6, which would then undergo an intramolecular allylation to produce the 2,6-trans-disubstituted dihydropyran 7. ${ }^{7,8}$ This process is related to the well established Prins cyclization reactions of homoallylic alcohols and aldehydes, which provide cis-2,6-disubstituted dihydropyrans preferentially..$^{9-14}$ However, owing to the strong stereoelectronic preference for the silyl substituent to adopt an axial position in reactions that develop carbocationic character at the $\beta$-position, ${ }^{15,16}$ we expected that the conversion of 5 to 7 would provide the 2,6-trans-dihydropyran selectively. Implicit in this prediction was the assumption that the intramolecular allylation would proceed by way of a chair-like transition state (as in 6). The stereochemistry of the trans-dihydropyran product then follows from the 3,4-anti stereochemistry of the allylsilane 5, which dictates that both the $\mathrm{R}$ group (deriving from the aldehyde used in the synthesis of 5) and the silyl substituent will adopt axial positions in $\mathbf{6}$, and the equatorial placement of the $\mathrm{R}$ ' substituent (deriving from the second aldehyde, R'CHO).

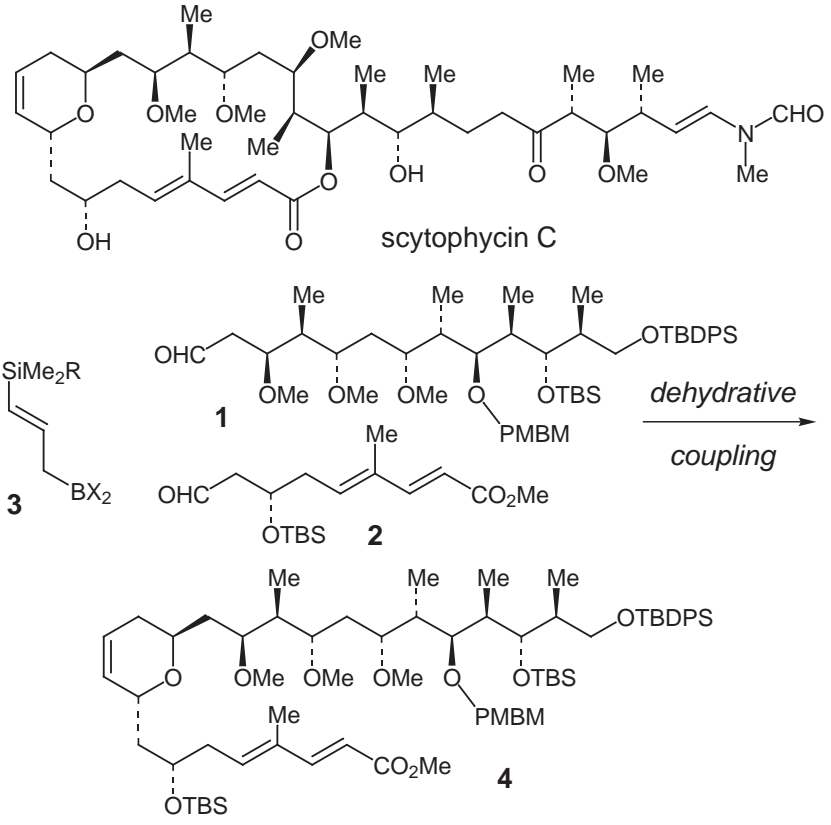

No examples of intramolecular allylation of the type 5 to 7 had been reported at the time that our studies were initiated. ${ }^{7,8}$ However, Speckamp had suggested that ions like $\mathbf{6}$ (with $\mathrm{R}^{\prime}=\mathrm{CO}_{2} \mathrm{Me}$ ) are intermediates in the vinylsilaneterminated cyclizations of ester-substituted oxocarbenium ions. ${ }^{17,18}$ Consequently, we anticipated that our method would intercept a known class of reactive intermediates by starting from $\mathbf{5}$, rather than from a vinylsilane precursor. ${ }^{8,19}$ While our studies were in progress, Panek reported an analogous method for the synthesis of substituted dihydropyrans via the reactions of $\beta$-hydroxycrotylsilanes and aldehydes. ${ }^{5}$ 
Initial studies were performed using allylsilane $\mathbf{8 a}^{4}$ and the corresponding TMS ether $\mathbf{8 b}$ as substrates. After screening a number of Lewis acid and solvent combinations, we settled on use of TMS-OTf in $\mathrm{CH}_{2} \mathrm{Cl}_{2}$ at $-78{ }^{\circ} \mathrm{C}$ in the presence of $4 \AA$ molecular sieves for these reactions. ${ }^{20,21}$ The optimal conditions for the reaction of $\mathbf{8 a}$ with dihydrocinnamaldehyde involved use of 3 equiv. of the aldehyde and 0.5 equiv. of TMS-OTf at a final concentration of $0.15 \mathrm{M}$ (for 8a). Under these conditions, an $82 \%$ yield of dihydropyran 9 was obtained with excellent stereoselectivity (94: 6 d.s.). Comparative experiments using $\mathbf{8 a}$ and the TMS ether $\mathbf{8 b}$ indicated that there was no significant advantage to use of $\mathbf{8 b}$ as the substrate. However, use of smaller amounts of aldehyde led to substantially decreased yields owing to competitive Lewis acid catalyzed Peterson elimination of $\mathbf{8 a} / \mathbf{8 b}$, as well as the TMSOTf promoted cyclotrimerization of the aldehyde. The Peterson elimination process was completely suppressed using the optimal conditions ( 3 equiv. RCHO, 0.5 equiv. TMS-OTf, $0.15 \mathrm{M}$ concentration of $\mathbf{8 a}$ ).

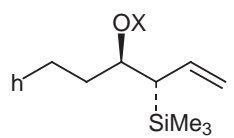

$8 \mathrm{a}, \mathrm{X}=\mathrm{H}$ 8b, $X=$ TMS

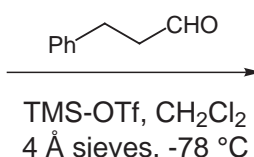

$4 \AA$ sieves, $-78^{\circ} \mathrm{C}$

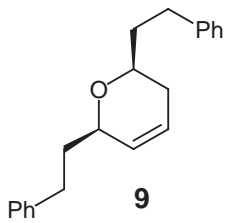

$\begin{array}{cc}\text { Substrate } & \mathbf{R C H O} \\ \mathbf{8 b} & 1.0 \text { eq. } \\ \mathbf{8 b} & 1.0 \text { eq. } \\ \mathbf{8 a} & 1.0 \text { eq. } \\ \mathbf{8 a} & 3.0 \text { eq. }\end{array}$

$\begin{array}{cc}\text { TMS-OTf } & \text { Conc. } \\ 1.0 \text { eq. } & 0.08 \mathrm{M} \\ 0.5 \text { eq. } & 0.14 \mathrm{M} \\ 0.5 \text { eq. } & 0.13 \mathrm{M} \\ 0.5 \text { eq. } & 0.15 \mathrm{M}\end{array}$

$\begin{array}{cc}\text { Yield } & \text { d.s } \\ 49 \% & 91: 9 \\ 38 \% & 94: 6 \\ \text { n.d. } & 95: 5 \\ 82 \% & 94: 6\end{array}$<smiles>C/C=C\[C@H]([AsH3])[C@@H](O)C(=O)OC(C)(C)C</smiles>

10

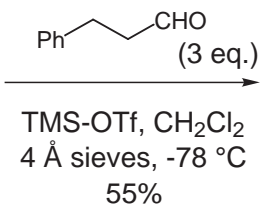
$55 \%$

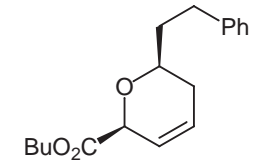

11, d.s. $85: 15$
Surprisingly, the major product of the reaction of 8a and dihydrocinnamaldehyde was the 2,6-cis-dihydropyran $\mathbf{9}$, and not the originally targeted trans diastereomer. The stereochemistry of $\mathbf{9}$ was easily assigned by hydrogenation $\left(\mathrm{H}_{2}, \mathrm{Pd} / \mathrm{C}\right)$ to the meso tetrahydrofuran $\left([\alpha]_{\mathrm{D}}=0\right)$, as well as by the observation of an NOE between the two axial hydrogens at $C(2)$ and $C(6)$ of $\mathbf{9}$. The reaction of $\mathbf{1 0}$ and dihydrocinnamaldehyde similarly provided dihydropyran 11 (85: 15 d.s., 57\% yield), again with the cis-isomer predominating (as confirmed by an NOE between $\mathrm{H}-2$ and $\mathrm{H}-$ $6)$.

Attempts to extend these results to additional hydroxyallylsilane-aldehyde combinations led to complex product mixtures. For example, the reaction of allylsilane 8a with isobutyraldehyde (1.0 equiv., using non-optimized conditions) gave three products after HPLC separation: the de- sired product 12 (12\%), dihydropyran 13 (17\%) that differs from 12 in terms of the placement of the double bond in the ring, and dihydropyran $9(7 \%)$ with two phenylethyl substituents! The same three products were obtained (70\% combined yield) from the reaction of allylsilane 14 with dihydrocinnamaldehyde (4 equiv.). In this case, the bis-phenylethyl substituted cis-dihydropyran 9 was obtained in 50\% yield, with the desired product $\mathbf{1 3}$ being isolated in $17 \%$ yield along with the olefin regioisomer 12 in 3\% yield (after HPLC separation). The cisstereochemistry of dihydropyrans $\mathbf{1 2}$ and $\mathbf{1 3}$ was assigned by ${ }^{1} \mathrm{H}$ NOE studies.
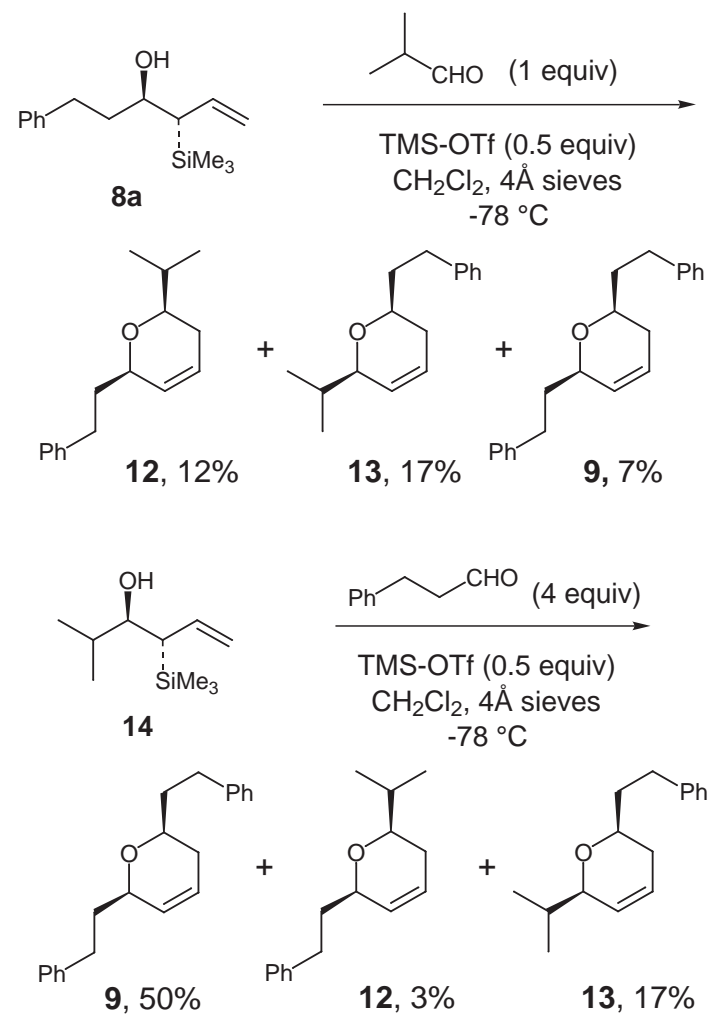

The side chain exchange process that complicates the reactions of allylsilanes 8a and $\mathbf{1 4}$ leading to unsymmetrically substituted dihydropyrans $\mathbf{1 2}$ and $\mathbf{1 3}$ can be suppressed by using $\alpha$-acetoxy acetals such as $\mathbf{1 6}$ and $\mathbf{1 9}$ as the cyclization substrates. The $\alpha$-acetoxy acetals were synthesized by using Rychnovsky's procedure for in situ acylation of the tetrahedral intermediates generated by DIBAL reduction of esters. ${ }^{22-24}$ The optimal conditions for cyclization of $\mathbf{1 6}$ involved use of $\mathrm{SnCl}_{4}$ (1.5 equiv.) in toluene at $-78{ }^{\circ} \mathrm{C}$ to $-15^{\circ} \mathrm{C}$. Under these conditions, the 2,6-cis-dihydropyran 17 was obtained in $66 \%$ yield with 94: 6 d.s., and the symmetrically substituted dihydropyran 9 (resulting from side chain exchange) was obtained in only $4 \%$ yield. As another illustration of this method, cisdihydropyran 9 was obtained in 50\% overall yield (94: 6 d.s.) for the three step sequence from $\mathbf{1 8}$. 


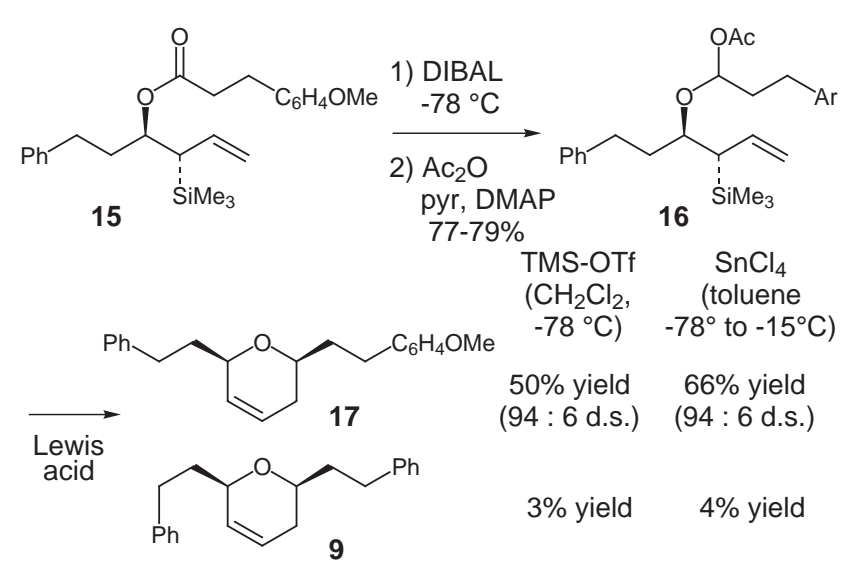

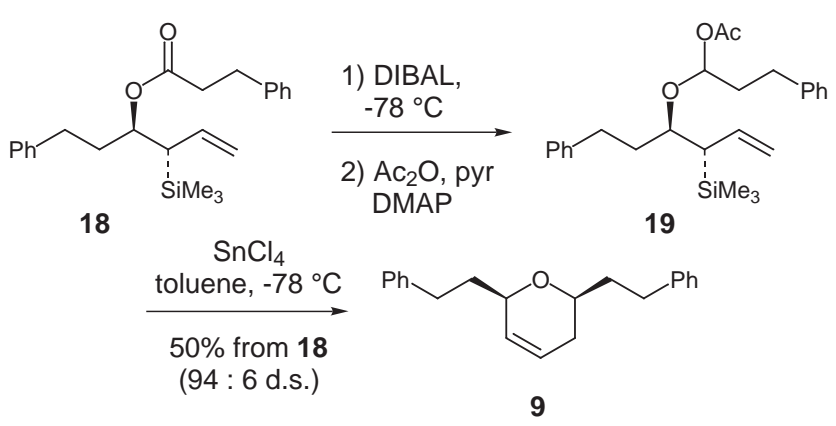

The preferential formation of the 2,6-cis-dihydropyrans and the unanticipated exchange of allylsilane side chains can be explained by invoking competitive and extremely facile oxonia-Cope rearrangements ${ }^{17,18,25}$ in the intramolecular allylation process. ${ }^{26} \mathrm{We}$ assumed at the outset that oxonium ion 22 (c.f., 6) would cyclize via a chair-like transition state to give the 2,6-trans-dihydropyran $\mathbf{2 3}$ (c.f., 7). However, the experimental record clearly establishes that this pathway $(\mathbf{2 2} \rightarrow \mathbf{2 3})$ is slow. We initially speculated that ion 22 undergoes a [3,3]-sigmatropic rearrangement, or an oxonia-Cope rearrangement, to give $\mathbf{2 4}$ in which the phenylethyl substituent adopts a thermodynamically unfavorable axial position. Oxonium ion $\mathbf{2 4}$ could isomerize to $\mathbf{2 5}$ with an equatorial phenylethyl substituent, by reversible addition of a nucleophile (e.g., TMS$\mathrm{OH}$ in the TMS-OTf catalyzed reactions of $\mathbf{8 a}$; chloride or acetate ions in the $\mathrm{SnCl}_{4}$ promoted reactions of the $\alpha$-acetoxy acetals, 20). Ion $\mathbf{2 5}$ is structurally equivalent to the intermediates generated by Speckamp and Markó from homoallylsilanols like 28. ${ }^{8,17-19}$ It could be expected that 25 would cyclize directly to the 2,6-cis-dihydropyran ent$\mathbf{2 7},{ }^{27}$ or undergo a facile reverse oxonia-Cope rearrangement to $\mathbf{2 6}$ which can then undergo intramolecular allylation to the 2,6-cis-disubstituted dihydropyran ent-27. The intermediacy of ions $\mathbf{2 4}$ and $\mathbf{2 5}$ also accounts for the side chain scrambling that occurs in the reaction of $\mathbf{8 a}$ with isobutyraldehyde and of $\mathbf{1 6}$ with dihydrocinnamaldehyde, as addition of TMS-OH to $\mathbf{2 4}$ or $\mathbf{2 5}$ creates the opportunity for release of dihydrocinnamaldehyde into solution and give 28, which can then recombine with the second aldehyde, $\mathrm{R}^{\prime} \mathrm{CHO}$, which is used in excess. ${ }^{28}$<smiles>PC1CC=CC(CCc2ccccc2)O1</smiles>

23, 2,6-trans
Prediction:

inversion of original C-O stereochemistry - $O$ stereochemistry
via chair $t . s .25$<smiles>CCO[Mg]</smiles>

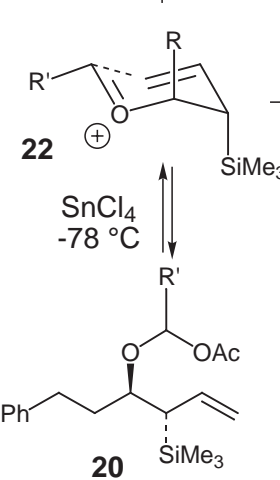<smiles>CCCCCCCCCCCCCCCCC</smiles>

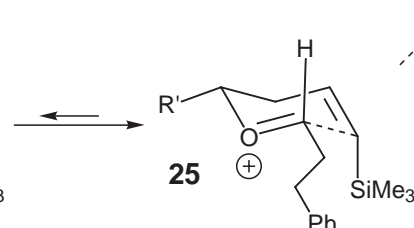
$\oplus$<smiles>C=C=CCCCCC</smiles>

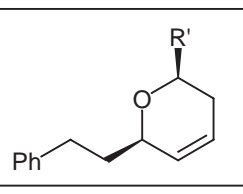

27, 2,6-cis<smiles>C=CC(CCc1ccccc1)C(C)O</smiles>

$8 \mathrm{a}$

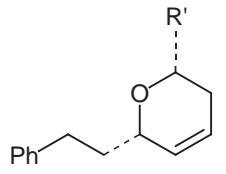

ent-27, 2,6-cis

Scheme Intervention of Oxonia-Cope Rearrangements in the Intramolecular Allylation Reaction 
A striking conclusion of this analysis is that if this process proceeds via the intermediacy of chair-like transition states, the 2,6-cis-dihydropyran ent-27 will be produced with inversion of the original C-O stereochemistry of $\mathbf{8 a}$. This stereochemical inversion occurs at the stage of the oxonium ion isomerization, $\mathbf{2 4} \rightarrow \mathbf{2 5}$. However, if the oxonia-Cope rearrangements and the intramolecular allylation proceed by way of boat-like transition structures $\mathbf{2 1}$ and $\mathbf{2 9}$, then the overall conversion of $\mathbf{8 a}$ or $\mathbf{2 0}$ to the 2,6cis-dihydropyran 27 will proceed with retention of stereochemistry.

We established that the cyclization reactions of the $\alpha$-acetoxy acetals proceed with retention of stereochemistry by the synthesis of 33, a known precursor of a civet cat pheromone..$^{29,30}$ Thus, treatment of $\alpha$-acetoxy acetal 31, prepared in $75 \%$ yield from ester $\mathbf{3 0}^{31}$ by using the Rychnovsky procedure, ${ }^{22,23}$ with TMS-OTf in $\mathrm{CH}_{2} \mathrm{Cl}_{2}$ at $78^{\circ} \mathrm{C}$ provided 32 in $41 \%$ yield (volatile!) with $94: 6$ selectivity. The 2,6-cis stereochemistry was confirmed by the observation of a NOE between H-2 and H-6. Hydrogenation of $\mathbf{3 2}$ over $\mathrm{Pd} / \mathrm{C}$ provided (-)-33, the stereochemistry of which was confirmed by comparison with two independent literature assignments. ${ }^{29,30}$

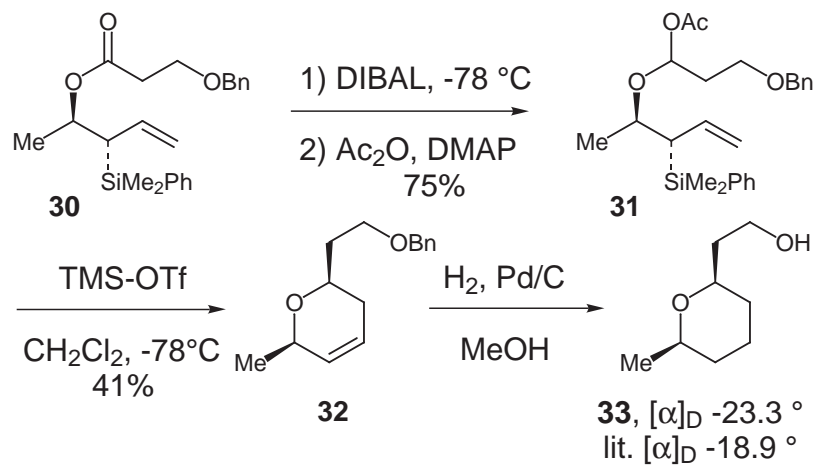

Armed with the knowledge that the cyclization of $\alpha$-acetoxy acetals proceeds with retention of stereochemistry, we established the absolute stereochemical course of the allylation reactions of hydroxyallylsilanes as well as the stereochemistry of the allylation process involving side chain scrambling. First, we showed that the $\mathrm{SnCl}_{4}$ promoted cyclization of $\mathbf{1 9}$ (93\% e.e.) provides $\mathbf{9}$ (94\% e.e.) with complete retention of stereochemistry as determined by chiral HPLC analysis. The TMS-OTf catalyzed dehydrative coupling of ent-8a (87\% e.e.) and dihydrocinnimaldehyde similarly proceeded with complete retention of stereochemistry, as cis-2,6-dihydropyran ent-9 was obtained with $87 \%$ e.e. Finally, dihydropyran 9 (86\% e.e.) was obtained from the dehydrative coupling of $\mathbf{1 4}$ (88\% e.e.) and dihydrocinnamaldehyde that proceeds by way of vinylsilane $28\left(\mathrm{R}^{\prime}=\mathrm{PhCH}_{2} \mathrm{CH}_{2}{ }^{-}\right)$with three $\mathrm{C}-\mathrm{C}$ bond forming reactions and loss of isobutyraldehyde from the starting allylsilane.<smiles>C=CC(CCc1ccccc1)C(CCc1ccccc1)OC(C)=O</smiles>

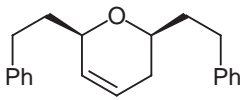

$19,93 \%$ e.e.<smiles>C=C[C@H](CCc1ccccc1)[C@@H](O)CC</smiles><smiles>O=CCCCc1ccccc1</smiles>
(3 eq)

TMS-OTf, $\mathrm{CH}_{2} \mathrm{Cl}_{2}$ $4 \AA$ sieves, $-78^{\circ} \mathrm{C}$

ent-8a, $87 \%$ e.e. $80 \%$<smiles>C=C[C@H](C(O)C(C)C)[As](C)(C)C</smiles>

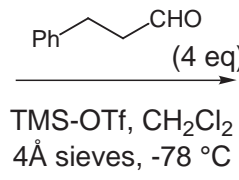

$14,88 \%$ e.e. $50 \%$
9, $94 \%$ e.e. retention

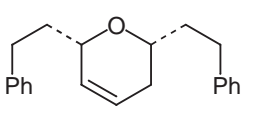

ent $-9,87 \%$ e.e. retention

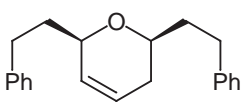

9, $86 \%$ e.e. retention

Based on these results, we conclude that all of the intramolecular allylation reactions leading to 2,6-cis-disubstituted dihydropyrans described in this paper, as well as the oxonia-Cope rearrangement reactions implicated in the side chain exchange process, proceed with high stereochemical fidelity via boat-like transition states (e.g., $\mathbf{8 a} /$ $\mathbf{2 0} \rightarrow \mathbf{2 1} \rightarrow \mathbf{2 7}$ for the allylation, and $\mathbf{8 a} \rightarrow \mathbf{2 1} \rightarrow \mathbf{2 9} \rightarrow \mathbf{2 8}$ $\rightarrow \mathbf{2 9} \rightarrow \mathbf{2 1} \rightarrow \mathbf{2 7}$ for the allylation process with exchange of the allylsilane side chain; see Scheme). Our results also explain the preferential formation of 2,6-cis-disubstituted dihydropyrans from the $\mathrm{InCl}_{3}$ mediated reactions of aldehydes and 3-trimethylsilylallyl tributylstannane recently described by Li and coworkers. ${ }^{9}$

We conclude by commenting briefly on the related dihydropyran synthesis recently reported by Panek. ${ }^{5}$ The dehydrative cyclizations of crotylsilanes $\mathbf{3 4}$ and $\mathbf{3 6}$ proceed with excellent selectivity to the substituted dihydropyrans

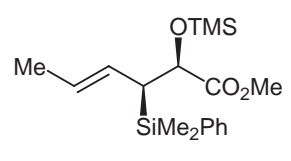

34<smiles>C/C=C/C([AsH2+])C(O[Na])C(C)=O</smiles>

36

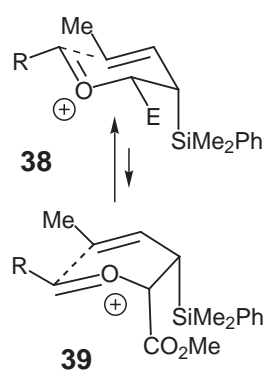

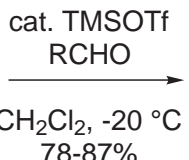

$78-87 \%$

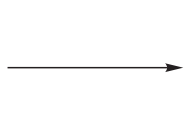

$35,9-15: 1$ d.s.<smiles>CC(=O)[C@H]1C=C[C@@H](C)[C@H](P)O1</smiles>

$37,10-30: 1$ d.s.

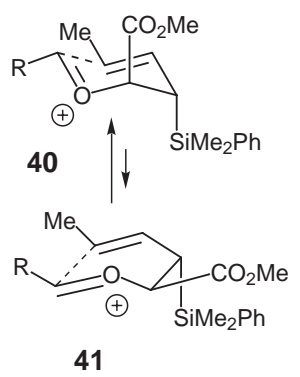


35 and 37, respectively. While Panek has suggested that these reactions proceed by way of boat-like transition states, ${ }^{32}$ we think it is more likely that they proceed by way of the chair like transition structures $\mathbf{3 8}$ (for $\mathbf{3 4}$ ) and 40 (for 36) because the boat-like transition states 39 and 41 (in which the oxonium ions adopt the more stable $(E)$ geometry) suffer from eclipsing interactions involving the aldehyde $\mathrm{R}$ group and the Me group deriving from the crotylsilane reagent; transition structure $\mathbf{3 9}$ also suffers from an eclipsing interaction between the axial carbomethoxyl and the pseudoaxial $-\mathrm{SiMe}_{2} \mathrm{Ph}$.

Based on these results, it appears that the boat-like transition state $\mathbf{2 1}$ in the reactions of the allylsilanes reported herein is favored owing to the absence of the eclipsing interactions highlighted in $\mathbf{3 9}$ and $\mathbf{4 1}$. Finally, we note that products deriving from oxonia-Cope rearrangements were not observed in the Panek study, a result that is consistent with the dehydrative cyclization reactions of carboalkoxy-substituted allylsilane 10. It may be inferred that the oxonia-Cope process is disfavored with intermediates $21\left(\mathrm{R}=\mathrm{CO}_{2} \mathrm{Bu}\right)$ since the electron withdrawing carboalkoxy group destabilizes the oxonia-Cope product 29 in which the $-\mathrm{CO}_{2} \mathrm{Bu}$ group is directly attached to the oxonium ion carbon. If this analysis is correct, then the dehydrative cyclization reactions of aldehydes and crotylsilanes analogous to $\mathbf{8 a}$ and $\mathbf{1 4}$, etc., will also experience competitive oxonia-Cope processes.

Additional studies on the stereoselective synthesis of 2,6trans-disubstituted dihydropyrans, required for our synthesis of scytophycin $\mathrm{C}$ and other natural products, are ongoing and will be reported in due course.

\section{Acknowledgement}

We gratefully acknowledge support provided the National Institute of General Medical Sciences (GM 38436).

\section{References and Notes}

(1) Taken in part from the $2000 \mathrm{Ph}$. D. Thesis of G. J. Dilley, University of Michigan.

(2) Roush, W. R.; Dilley, G. J. Tetrahedron Lett. 1999, 40, 4955.

(3) Roush, W. R.; Grover, P. T. Tetrahedron 1992, 48, 1981.

(4) Roush, W. R.; Pinchuk, A. N.; Micalizio, G. C. Tetrahedron Lett. 2000, 41, 9413.

(5) Huang, H.; Panek, J. S. J. Am. Chem. Soc. 2000, 122, 9836, and references cited therein.

(6) Allyltrimethylsilanes of general structure 5 were synthesized by allylboration of aldehydes with the chiral allylborane reagent generated by metallation of allyltrimethylsilane with $n$ - $\mathrm{BuLi}$ and $\mathrm{KO} t \mathrm{Bu}$ in THF at $-25^{\circ} \mathrm{C}$ followed by addition of
$\mathrm{MeOB}(\mathrm{Ipc})_{2}$ at $-78^{\circ} \mathrm{C}, \mathrm{BF}_{3} \cdot \mathrm{Et}_{2} \mathrm{O}$ and then an aldehyde (see ref. 4 for a related procedure), or by using the DIPT modified (E)- $\gamma$-trimethylsilylallylboronate (Marron, T. G.; Roush, W. R. Tetrahedron Lett. 1995, 36, 1581).

(7) Markó, I.; Mekhalfia, A. Tetrahedron Lett. 1992, 33, 1799.

(8) Markó, I. E.; Bayston, D. J. Tetrahedron 1994, 50, 7141.

(9) Viswanathan, G. S.; Yang, J.; Li, C.-J. Org. Lett. 1999, 1, 933.

(10) Cloninger, M. J.; Overman, L. E. J. Am. Chem. Soc. 1999, $121,1092$.

(11) Rychnovsky, S. D.; Hu, Y.; Ellsworth, B. Tetrahedron Lett. 1998, 39, 7271.

(12) Markó, I.; Chellé, F. Tetrahedron Lett. 1997, 38, 2895.

(13) Markó, I. E.; Mekhalfia, A.; Bayston, D. J.; Adams, H. J. Org. Chem. 1992, 57, 2211.

(14) Coppi, L.; Ricci, A.; Taddei, M. J. Org. Chem. 1988, 53, 911.

(15) Lambert, J. B.; Finzel, R. B. J. Am. Chem. Soc. 1982, 104, 2020.

(16) Lambert, J. B.; Wang, G.-T. J. Phys. Org. Chem. 1988, 1, 169.

(17) Lolkema, L. D. M.; Semeyn, C.; Ashek, L.; Hiemstra, H.; Speckamp, W. N. Tetrahedron 1994, 50, 7129.

(18) Semeyn, C.; Blaauw, R. H.; Hiemstra, H.; Speckamp, W. N. J. Org. Chem. 1997, 62, 3426.

(19) Markó, I. E.; Dobbs, A. P.; Scheirmann, V.; Chellé, F.; Bayston, D. J. Tetrahedron Lett. 1997, 38, 2899.

(20) Imwinkelried, R.; Seebach, D. Angew. Chem. Int. Ed. Engl. 1985, 24, 765 .

(21) Mekhalfia, A.; Markó, I. Tetrahedron Lett. 1991, 32, 4779.

(22) Dahanukar, V. H.; Rychnovsky, S. D. J. Org. Chem. 1996, 61, 8317.

(23) Kopecky, D. J.; Rychnovsky, S. D. J. Org. Chem. 2000, 65, 191.

(24) Esters $\mathbf{1 5}$ and $\mathbf{1 8}$ were prepared by acylation of $\mathbf{8 a}$ with the appropriate acid chlorides (DMAP, pyridine, $\mathrm{CH}_{2} \mathrm{Cl}_{2}$ ) in 82 $84 \%$ yield.

(25) Sumida, S.; Ohga, M.; Mitani, J.; Nokami, J. J. Am. Chem. Soc. 2000, 122, 1310.

(26) Analogous aza-Cope rearrangements of iminium ions have been documented previously: Daub, G. W.; Heerding, D. A.; Overman, L. E. Tetrahedron 1988, 44, 3919.

(27) Blumenkopf, T. A.; Overman, L. E. Chem. Rev. 1986, 88, 857.

(28) Loss of the original side chain also occurs in iminium ionvinylsilane cycilzations which proceed via aza-Cope rearrangements: Castro, P.; Overman, L. E.; Zhang, X.; Mariano, P. S. Tetrahedron Lett. 1993, 34, 5243.

(29) Mandai, T.; Ueda, M.; Kashiwagi, K.; Kawada, M.; Tsuji, J. Tetrahedron Lett. 1993, 34, 111.

(30) Edmunds, A. J. F.; Trueb, W. Tetrahedron Lett. 1997, 38, 1009.

(31) Chiral allylsilane $\mathbf{3 0}$ was synthesized from the corresponding homoallylic silanol that was prepared as described in ref. 4 . The absolute stereochemistry of the alcohol was assigned by using the modified Mosher ester method.

(32) Panek's analysis indicates that the favored boat-like transition states have the thermodynamically less favorable $(Z)$ oxonium ion geometry.

Article Identifier:

1437-2096,E;2001,0,SI,0955,0959,ftx,en;Y02301ST.pdf 